\title{
Height of Iranian Children Age 7-18 in Comparison with WHO (2007), CDC (2000) and NCHS (1977) Global Standards: A Systematic Review and Meta- Analysis
}

\author{
Asou Yazdani \\ Ilam University of Medical Sciences \\ Saba Shakarami \\ Ilam University of Medical Sciences \\ Reza Najafi \\ Ilam University of Medical Sciences \\ Miremad Moafi-Madani \\ Ilam University of Medical Sciences \\ Mostafa Dianatinasab ( $\nabla$ dianati.epid@shmu.ac.ir) \\ Shahrood University of Medical Sciences https://orcid.org/0000-0002-0185-5807 \\ Kourosh Sayehmiri \\ Ilam University of Medical Sciences
}

Research article

Keywords: Stunting, Height, Growing Child, School Age, NCHS

Posted Date: January 16th, 2020

DOI: https://doi.org/10.21203/rs.2.20992/v1

License: (c) (i) This work is licensed under a Creative Commons Attribution 4.0 International License.

Read Full License 
2 Running title: Height of Iranian Children Age 7-18 in Comparison with Global Standards

4 Height of Iranian Children Age 7-18 in Comparison with WHO (2007), CDC (2000) and NCHS (1977) Global Standards: A Systematic Review and Meta-Analysis

Asou Yazdani ${ }^{(1)}$, Saba Shakarami ${ }^{(2)}$, Reza Najafi ${ }^{(3)}$, Miremad Moafi-Madani ${ }^{(4)}$, Mostafa Dianatinasab ${ }^{\left(5^{*}\right)}$, Kourosh

${ }^{1}$ M.Sc. of Biostatistics and Member of Student Research Committee, School of Public Health, Ilam University of Medical Sciences, Ilam, Iran

${ }^{2}$ M.Sc. of Epidemiology and Member of Student Research Committee, School of Public Health, Ilam University of Medical Sciences, Ilam, Iran

${ }^{3}$ Pediatric Endocrinologist, Department of Pediatrics, School of Medicine, Ilam University of Medical Sciences, Ilam, Iran.

${ }^{4}$ Medial Doctor, Mashhad University of Medical Sciences, Mashhad, Iran

${ }^{5}$ Department of Epidemiology, Center for Health Related Social and Behavioral Sciences Research, Shahroud University of Medical Sciences, Shahroud, Iran. Email: dianatinasab@sums.ac.ir

*Corresponding author(s):

23 Mostafa Dianatinasab,

24 Department of Epidemiology, Center for Health Related Social and Behavioral Sciences Research, Shahroud

25 University of Medical Sciences, Shahroud, Iran.

26 Email: dianati.epid@shmu.ac.ir 


\section{Abstract}

2 Background: Growth assessment based on standardized height and weight tables and charts is an essential part of healthcare monitoring and services for children and adolescents. The present systematic and meta-analysis study aimed to determine the height of Iranian children aged 7 to 18 years and compare it with the global standards.

Methods: A meta-analysis was performed on all relevant studies published until November 2018. The databases Iranmedex, Magiran, SID, IranDoc, Medline, Scopus, PubMed, Science Direct, Web of Knowledge, Cochrane and Google Scholar were searched using mesh and non-mesh keywords. Findings of the reviewed studies were compiled using the random effects model. Data heterogeneity was calculated using the $\mathrm{Q}$ statistic and the $\mathrm{I}^{2}$ index.

Results: 37 articles were found eligible for inclusion in the meta-analysis. The total sample size in these studies was 395,210 , consisting of 189,985 males and 205,372 females. The mean height of 18 -year-old Iranian girls ( $\bar{X}=157.75, \% 95 \mathrm{CI}: 156.79$ to 158.71$)$ was, respectively, $5.30,5.38,5.37 \mathrm{~cm}$ lower than the reference figures given by WHO $(\bar{X}=163.05)$, CDC $(\bar{X}=163.13)$, and NCHS $(\bar{X}=163.12)$. Similarly, the mean height of 18 -year-old Iranian boys $(\bar{X}=171.09, \% 95 \mathrm{CI}: 169.72$ to 172.47$)$ was, respectively, 5.05, 5.09, $5.07 \mathrm{~cm}$ lower than the WHO $(\bar{X}=176.14), \mathrm{CDC}(\bar{X}=176.18)$, and NCHS $(\bar{X}=176.16)$ standards.

Conclusions: Given the slightly different growth pattern and low mean height of Iranian girls and boys compared to the global standards, it is imperative to develop and provide more generalizable growth charts for Iranian children in order to improve the quality of growth assessment undertaken for these age groups.

Keywords: Stunting; Height; Growing Child; School Age; NCHS 


\section{Background}

2 Growth assessments are an essential part of healthcare monitoring and services for children and

3 adolescents (1-3). Height and weight measurements are highly valued because of the wealth of

4 information they provide for studies on the growth, diet and nutrition, and health of younger people as

5 they develop (4). Growth pattern assessments are excellent measures for multidimensional analysis of

6 growth variations over successive generations and their relationship with the environmental factors.

7 Such assessments are typically performed by the use of standardized height and weight charts and tables

8 developed by the World Health Organization (WHO), United States Centers for Disease Control and

9 Prevention (CDC), United States National Center for Health Statistics (NCHS), and other internationally

10 accredited organizations based on the anthropometric indicators of healthy children (8).

11 In Iran, as in many other countries, the lack of local standards has led to the use of standardized charts

12 and tables of NCHS as references. Since 1978, WHO has recognized these charts, including the latest

13 version published in 2007, as the global growth standard (11). Considering the variety of genetic, racial,

14 geographic, economic, and social factors involved in the growth process and the fact that reference

15 figures and natural growth patterns vary with the population, these reference charts can lead to erroneous

16 conclusions (13). For example, various studies have shown that the average height of many countries

17 has increased over time $(19,20)$. In Europe, the average height of adults has been on an increase since

18 the middle of the nineteenth century, but while this increase has been about one centimeter per decade

19 in northern Europe (20), it has been three centimeters per decade in southern and eastern Europe (13).

20 In the Netherlands, the average height has increased from $165 \mathrm{~cm}$ in 1860 to $181 \mathrm{~cm}$ in 1990 , making the

21 Dutch the tallest nation in the world (20). This trend has also occurred in the United States, which has

22 the world's most racially diverse population, but the increase in height-for-age has been about 7

23 centimeters or $4 \%$ less than in northern Europe (19). Several anthropometric studies conducted in

24 different parts of Iran show major discrepancies in terms of height percentiles with each other and with

25 the global standards $(2,27-29)$. Therefore, a closer examination of the issue is necessary, firstly because

26 of the role of growth factors as major metrics for long-term improvement in the public health, and

27 secondly to illustrate the various dimensions of generational changes in growth indices $(34,35)$.

28 The growth trends in Iranian students aged 7 to 18 years have been the subject of multiple studies, most 
1 of which have reported some differences from the global standards. However, this is the first 2 comprehensive meta-analysis of all studies carried out so far on this subject. In this systematic review

3 and meta-analysis, the authors screened and compiled the existing reports on the average height of 7 to

4 18-year-old Iranian boys and girls and compared the findings with the global standards so as to 5 contribute to the development of a clear and explicit local measure for the growth pattern assessment of 6 Iranian children and adolescents.

\section{$8 \quad$ Methods}

\section{$9 \quad$ Search strategy}

10 The review study was designed in accordance with the protocols of Systematic Review and Meta11 Analysis (PRISMA) (38). The target material was all studies published in Persian or English until 12 November 2018. The search was performed in national and international electronic databases including 13 Iranmedex, Magiran, SID, IranDoc, Medline, Scopus, PubMed, Science Direct, Web of Knowledge, 14 Cochrane and Google Scholar search engine. The search was conducted by two researchers (S.Sh and 15 A.Y) independently using identical keywords. Any disagreement was settled by the third researcher 16 (S.Sh) and the final consensus was reached through group discussion. For Persian databases, the 17 searched keywords were the Persian equivalents of height, students aged 7 to 18 years, and Iran. For 18 English databases, the search was performed with mesh terms: Growth Disorders, Stunting, Body 19 Height, Height, Length, Child, Growing Child, School Age OR 7 to 18 Years, and Iran. To expand the search, it was repeated with a combination of mesh and non-mesh terms and AND and OR functions.

21 The reference list of articles was also reviewed. In the event of any ambiguity, inaccuracy, or missing data, one of the researchers (R.N) contacted the authors via email up to two times. The bibliography of

23 the found articles was also manually searched to identify more possibly relevant articles (A.Y).

\section{Screening}

\section{Inclusion and exclusion criteria}

26 Two of the researchers (AY, KS) screened the articles based on the following inclusion criteria: 1) 27 descriptive design, 2) the studied population being 7 to 18 years old, 3 ) provision of (mean \pm standard 28 deviation) or (mean \pm standard error of the mean) for the studied population, and 4) being focused on 
1 Iran. The exclusion criteria were: 1) non-random sampling, 2) irrelevance to the subject, 3) and article's

2 lack of sufficient data for meta-analysis.

3

\section{Data extraction}

5 The quality of the articles was evaluated using the STROBE checklist (43). The authors adopted a simple

6 procedure for quality scoring. In this procedure, two of the researchers (S.Sh and A.Y), working

7 independently, gave each part of the checklist a score between 0 and 2, and the articles with total scores

8 of 1-15, 16-30, and 31-44 were classified as poor, moderate and high quality respectively. The articles

9 that earned a score of less than 16 (poor quality) were excluded from the meta-analysis process. Out of

10 the 37 works reviewed, 33 articles, which all had a cross-sectional-observational design, were found

11 eligible for data extraction. The required data were extracted by one of the researchers (A. Y) with the

12 help of a prepared checklist. This checklist was designed to facilitate the organized collection of the

13 data pertaining to the year of publication, age, gender, place of study, sample size, and mean and

14 standard deviation (SD) for all subjects. In the cases where the standard error of the mean (SEM) was

15 reported, the researchers converted it to the standard deviation. Stunting was defined as height-for-age

16 shorter than 3rd percentile or 2 SD below the median of NCHS/WHO growth reference (45). Height

17 reports of all studies were compared with the 50th percentile of the global height reference.

\section{Statistical analysis}

19 Data analysis was performed using STATA version 14.2. The results of the studies were combined using

20 the random effects model. Data heterogeneity was measured with Q statistic and $\mathrm{I}^{2}$ index. The level of

21 significance was considered to be $\mathrm{P}<0.05$. The analysis was performed in subgroups based on the year

22 of publication, age, gender, study area, sample size, and mean and SD or SEM of the height. A meta-

23 regression was also performed to determine the relationship of the reported heights with the date of

24 report and sample size. Since the effect size was being analyzed for a normally distributed quantitative variable, the mean and standard deviation of the heights were used and the standard error of the study

26 was obtained from the equation $\frac{\sigma^{2}}{n}$.

27 The total mean height was calculated by two methods. The first method is the weighted averaging using 
1 the equation weighted mean $=\frac{\sum w_{i} \hat{y}_{i}}{\sum w_{i}}$, where $\hat{y}_{i}$ is the effect size of study $\mathrm{i}$, and $W_{i}$ is the

2 weight of that study, which here is proportional to the size of the studied population, that is, the 3 population of the province where the study has been conducted. The second method is the meta-analysis

4 of fixed and random effects based on data heterogeneity. In this method, instead of the population of the

5 province, the weights are calculated based on the sample size and the mean error of samples. In this

6 method, the $95 \%$ confidence interval is calculated using the equation $\bar{Y} \pm z_{\frac{\alpha}{2}} \times \frac{S_{y}}{\sqrt{n}}$.

7 With these explanations, the mathematical formulation of the fixed and random models can be written 8 as follows:

$9 \hat{y}=\frac{\sum \hat{y}_{i} w_{i}}{\sum w_{i}}$ with $\quad w_{i} \approx \frac{1}{v_{i}}$

10 where

$11 \hat{y}_{i}=$ value of the parameter in study $\mathrm{i}$

$12 v_{i}=\quad$ variance of the parameter in study $\mathrm{i}$

$13 \hat{y}=$ point estimate of the parameter after combining the results of all studies

14 According to the above formula, the parameter estimate is equal to the weighted sum of parameter values

15 reported in different studies. In this formula, the weight of each study is inversely proportional to the

16 variance of the parameter in that study. In case of using the inverse variance, the weight of each study

17 will be directly proportional to the inverse variance.

18 In the fixed model, it is assumed that $\hat{y}_{i}$ follows a normal distribution, or:

$19 \hat{y_{i}} \approx N\left(y, v_{i}\right)$

20 This means that the observations made in the studies have a normal distribution with a fixed mean ( $y$

21 for the entire population) and a variance of $v_{i}$. In the random model, it is assumed that:

$22 \hat{y}_{i} \approx N\left(y, v_{i}\right) \quad$ and $\quad \mathrm{y}_{i} \approx N\left(\mathrm{y}, \mathrm{v}_{i}\right)$

23 This means that the observations made in each study follow a normal distribution with a mean equal to 
1 the mean in the same population $\left(\mathrm{y}_{i}\right)$, and the parameters in different populations have a normal

2 distribution with a mean equal to that parameter in all populations (y) and a variance of $\tau^{2}$. Hence, the 3 observed differences have two origins $\left.\left(\tau^{2}, v\right)\right)$. Heterogeneity across studies was evaluated by using the 4 Q statistics at the $\mathrm{P}<0.10$ level of significance. We also calculated the $\mathrm{I}^{2}$ statistic, which describes the 5 total variation across studies attributable to heterogeneity rather than chance; an $\mathrm{I}^{2}$ value greater than $650 \%$ indicates at least moderate heterogeneity and potential publication bias was assessed by visual 7 inspection of Begg's funnel plots.

\section{Results}

10 In the initial systematic search, a total of 528 articles were identified. Of these, 215 articles were 11 duplicates and 191 were irrelevant, hence leaving 122 articles eligible for full-text review. After this 12 review, 37 of these articles were excluded because of inconsistency in terms of target population, 28 13 were excluded because of missing data, and 17 were excluded because of not meeting the 14 inclusion/exclusion criteria. The remaining 40 articles were subjected to quality evaluation and 37 of 15 them were found eligible for inclusion in the final analysis (Figure 1).

17 The total sample size of the 37 articles included in the meta-analysis was 395,210 , of which 189,985 18 were male and 205,372 were female. These studies were published in Iran between 1991 and 2017. The 19 profile of the studies included in the meta-analysis is presented in Table 1

21 As shown in Figure 2, the mean height of 18-year-old Iranian girls was $157.75 \mathrm{~cm}$ (95\% confidence 22 interval: $156.156-158.72)$ and for boys, this figure was 171.09 (95\% confidence interval: 169.72-172.

23 47). The lowest and highest heights reported for 18-year-old Iranian girls were related to, respectively, 24 the study of Mostafa Hosseini (1991) (5), which reported an average height of $153 \mathrm{~cm}$ (confidence 25 interval: 152.89-153-10) for Iranians girls across the country, and the study of Akhi (2007) (34), which 26 reported an average height of $161 \mathrm{~cm}$ (confidence interval: 160.72-161.26) for the city of Sari, 27 Mazandaran (A). For 18-year-old Iranian boys, The lowest and highest reported heights were in, 
1 respectively, the study of Mohsen Hosseini (2017)(49), which reported an average height of $164 \mathrm{~cm}$

2 (confidence interval: 163.89-164.10) for Isfahan, and the study of Mehporvar (2015) (47), which

3 reported an average of $174.44 \mathrm{~cm}$ (confidence interval: 174-174.87) for Yazd (B).

5 According to the results presented in Figure 3, the mean height of Iranian girls and boys is lower than

6 the global standards. The results also show that Iranian girls and boys in the age group of 7 to 12 years

7 are only slightly shorter than the global references, but this difference widens from the age of 14 in girls

8 and 13 in boys. For example, Table 2 shows that at the age of 12, Iranian girls are 4.00, 4.25, and 3.96

$9 \mathrm{~cm}$ shorter than the WHO, NCHS and CDC standards, but at the age of 16, this difference widens to

$105.11,5.10$, and $5.14 \mathrm{~cm}$, respectively, and remains the same at least until the age of 18 years. For Iranian

11 boys, the difference from the WHO, NCHS and CDC standards is 5.40, 5.76, and $5.44 \mathrm{~cm}$ at the age of

1213 , slightly changes to $5.20,5.74$, and $5.63 \mathrm{~cm}$ at the age of 16 and remains the same at least until the

13 age of 18. In other words, these differences from the global standards vary with the gender. For girls,

14 the difference starts at the age of 12 and reaches a maximum of about $5 \mathrm{~cm}$ at the age of 18 . But for

15 boys, the difference from the global standards remains almost constant as they go through childhood

16 and adolescence.

17 According to the results of meta-regression analysis, the final height of 18 -year-old Iranian girls and

18 boys has not significantly changed with the year of the study. No statistically significant difference was

19 observed in this regard for boys $(\mathrm{P}=0.20)$ or girls $(\mathrm{P}=0.11)$ (Table 3$)$. Figure 4 shows meta-regression

20 analysis of random effects model of the mean height of 18-year-old Iranian girls and boys

22 The results of Table 4 show that among 18-year-old girls of different ethnicities, those belonging to 23 Kurd and Baluch ethnicities have respectively the highest $(159.27 \mathrm{~cm})$ and lowest $(155.33 \mathrm{~cm})$ mean

24 height. Similarly, among 18-year-old boys, those belonging to Kurd and Baluch ethnicities have the highest $(173.72 \mathrm{~cm})$ and lowest $(170.03 \mathrm{~cm})$ mean height.

27 Although the funnel plot was slightly asymmetric, after using the trim-and-fill method, visual inspection 28 of Begg's funnel plot did not identify substantial asymmetry for WD studies. Figures not presented here 
to save the limited space.

\section{Discussion}

4 To the best of our knowledge, this is the first systematic review and meta-analysis on the height of

5 Iranians aged 7 to 18 years in comparison with WHO, NCHS, and CDC standards. In this study, the

6 growth patterns of Iranian girls and boys were found to be different from the reference patterns. Meta-

7 analysis of studies conducted on 398,758 male and female students showed that Iranian girls of age 10

8 to 13 are averagely taller than Iranian boys of the same age, but this relation reverses at higher ages. The

9 same trend is present in the WHO standard, but in CDC and NCHS, it starts from the age of 11 instead

10 of 10. In the previous studies, this trend has been attributed to the earlier onset of puberty in girls (50).

11 Research has shown that the mean age of menarche in Iran is lower than in developed countries (51).

12 For example, the mean age of menarche is 12.43 in the United States (52), 13.1 in Norway (53), 12.27

13 in Indonesia (54), 12.6 in Colombia (55) and 12.4 in Mexico (56). It is widely known that there are

14 major differences in the age of menarche in different countries and different raced, but the specific reasons for these differences are still not well understood (57). Besides race, multiple factors including

16 biological, social, nutritional, geographical and lifestyle conditions may affect the age of menarche, but

17 overall, early or late onset of menarche cannot be attributed any one factor $(58,59)$.

18 Since the meta-analysis showed that the average height of Iranian girls and boys exhibit an almost

19 uniform pattern from the age of 16 to 18 , the mean height at the age of 18 was chosen for the final comparison with the global standards. In this comparison, it was found that the mean height of 18-yearold Iranian girls is, respectively, 4.67, 4.75, and $4.74 \mathrm{~cm}$ lower than the WHO, CDC, and NCHS standards. For 18-year-old Iranian boys, the mean height is $4.58,4.62$, and $4.60 \mathrm{~cm}$ lower than the WHO, CDC and NCHS standards. In these findings, the mean heights of Iranian girls and boys of all ages were closer to the WHO figures than to other standards. The results also showed a $13.18 \mathrm{~cm}$ difference in the mean height of Iranian boys and girls at the age of 18, whereas this difference is respectively 13.09, 13.05 and $13.04 \mathrm{~cm}$ in WHO, CDC, and NCHS standards. According to the results of the meta-analysis, the weighted means of the height of Iranian girls and boys of all ages were also lower than the reference standards. All meta-analyses are based on the assumption 
1 that sampling has been random and not stratified. For example, if a study has taken a sample of 500 2 people from Ilam province, which has a population of 600,000 people, and another study has taken a 3 sample of 500 people from Tehran province, which has a population of 12 million people, then In meta4 analysis, weighting to studies is based on inverse variance and sample size we do not give weight to studies base of province population of studies, when we pooled studies we give same weight to all of 6 provinces. But in weighting mean method we use of structure, stratify sampling and population of 7 provinces and sample size of studies accounted in the total mean. As a result, this weighted mean is more accurate than the other mean discussed above. The weighted mean height of 18-year-old Iranian

9 girls was found to be $3.40,3.48,3.47 \mathrm{~cm}$ lower than the WHO, CDC and NCHS standards. For 18-yearold Iranian boys, the weighted mean of the height was $3.76,3.80,3.78 \mathrm{~cm}$ lower than the WHO, CDC and NCHS standards, respectively. The weighted mean height of girls and boys at the age of 18 was 12 closer to the WHO reference values than to other standards, nevertheless, there is a substantial difference 13 between the growth trends of Iranian girls and boys and those of the global standards.

14 The above findings are consistent with the results of Ulijaszek et al. (2001), which after studying the 15 mean height of 7-year-old students in numerous studies, reported that the mean height of Asian 16 populations is approximately $1.0-1.7 \mathrm{~cm}$ lower than that of other demographic groups in Europe, Africa, 17 North America, and South America (60). A study conducted on students aged 6 to 16 in Sagamu, 18 Nigeria, showed that the mean height of these students was lower than the WHO and CDC references 19 and generally closer to the former than the latter (61). The findings of the present work are also in agreement with the reports of studies conducted in Italy, Turkey and Saudi Arabia, which showed that,

21 for most ages, stature growths were lower than the reference figures (62-64). A study on the growth of 22 Nigerians aged 1 to 20 also showed that the 50th percentile of children growth chart was lower than that of WHO/FAO standard (65). On the other hand, these findings were inconsistent with the results of a study by Razzaghy et al. (2006), which reported that the height of Iranian boys aged 6 to 15 are comparable to the CDC figures and local standards are only needed for girls of 6 to 17 years old (6). The results are also inconsistent with the findings of Bener et al. (2005) and Fuiano et al. (2005) (66, 27 67).

28 These inconsistencies can be attributed to the populations studied in those works. For example, the study 
1 of Razzaghy was conducted on the children of school age in Tehran, which can be hardly generalized

2 to the entire population of Iranian children and adolescents. It should also be noted that the growth rate

3 of girls and boys in different regions is a function of numerous factors. In this regard, some studies have

4 suggested that children who enjoy a better social and economic status are taller than others $(45,68)$. In

5 another study, race was highlighted as a key factor for the height of children and statistically significant

6 differences were shown between the growth curves of black and white people (69). However, several

7 studies have questioned the role of race in growth indices. For example, Droomers et al. (1995) showed

8 that Indonesian children with high socioeconomic status had higher height and weight than American

9 children (70). Also, the results of a systematic study showed that in low-income and middle-income

10 countries, children living in urban areas are taller than their rural peers (70). The role of health services,

11 education level, and nutritional diet on the height is also well recognized (68). A number of studies have

12 also underscored the role of genetic and environmental factors such as malnutrition, growth retardation,

13 and infection as factors influencing the anthropometric indices in developing countries $(71,72)$.

14 The comparison of height indices of Iranian boys and girls with their European and American peers

15 shows significant discrepancies, which can be attributed to differences in environmental, socio-

16 economic, educational, lifestyle, and diet factors. Considering the significant difference between the mean heights of Iranian girls and boys and the global standards, it can be stated that these standards,

18 which are based on the population of American children, are ill-suited for the population of Iranian 19 children and adolescents (71). Because of genetic, economic, social and cultural differences, the existing criteria, which are mostly based on the population of people living in advanced Western nations, cannot

21 be valid for all countries across the world. In addition, relying on the growth indicators designed based 22 on non-local populations may lead to false diagnoses of underweight and short stature (49). The use of 23 global standards can also have secondary effects such as the promotion of ill-fitting ergonomic designs 24 for chairs and tables, which may increase the prevalence of musculoskeletal problems in the local population (73). The results of this study provide evidence in support of the notion that regional growth standards should be developed according to racial, genetic, and geographical specification of each country so that they could be relied upon for use in local studies on health or growth disorders. 
1 The main limitation of this study was the skewed geographical distribution of the reviewed studies,

2 which was reflected in the fact that some provinces had multiple representatives while others had no 3 representative in the analyzed data. The main strength of this work is the large size of the compiled 4 sample, which makes the findings more generalizable for the broader population of Iranian children and 5 adolescents. The findings of this research are based on a sample of about 398,000 people living in 6 different cities across Iran, and considering that height is a quantitative variable, this sample can be 7 considered large enough for reasonable generalization of the results to the whole country. Hence, this is 8 the most accurate estimate of the height status of Iranian girls and boys in different age groups from 7

9 to 18 . The results of this meta-analysis are also consistent with the findings of a study conducted in 2015

10 by Mehrparvar $(46,47)$, which is currently the largest nation-wide anthropometry study carried out on 11 six major ethnicities of Iran (Kurd, Lor, Turk, Arab, Persian, and Baluch).

\section{Conclusion}

14 Given the different growth pattern and low mean height of Iranian girls and boys compared to the global standards, the use of these reference charts for Iranian children and adolescents may lead to erroneous conclusions. Therefore, development and promotion of regional growth charts for Iranian children and adolescents seem necessary for reliable evaluation of growth trends and more effective health policy planning in relation to these age groups.

20 Abbreviations

21 World Health Organization (WHO), United States Centers for Disease Control and Prevention (CDC),

22 United States National Center for Health Statistics (NCHS), protocols of Systematic Review and Meta23 Analysis (PRISMA), standard deviation (SD), standard error of the mean (SEM).

\section{Declarations}

\section{Ethics approval and consent to participate}

26 The research proposal was approved by the Ethics Committee affiliated with Ilam University of

27 Medical Sciences. This is a systematic review study then no ethical approval or consent to 
1 participate is applicable to this study.

\section{Consent for publication}

$3 \quad$ Not applicable

\section{$4 \quad$ Availability of data and materials}

5 The datasets used and analyzed during the current study are available from the corresponding

6 author on reasonable request.

\section{$7 \quad$ Competing interests}

8 The authors stated no conflict of interest.

\section{$9 \quad$ Funding}

10 Not provided. No fund

\section{Authors' contributions}

12 All authors contributed extensively to the work presented in this paper. AY and MD designed 13 the study. SS, RN, and KS conceived the study. MM, AY, and SS created and performed the 14 literature search strategy, AY built the data extraction file, AY and SS performed the data extraction 15 and MD and KS supervised the process. MD and KS performed the statistical analyses, and all 16 authors interpreted the data. $\mathrm{MM}$ and $\mathrm{RN}$ drafted and revised the manuscript, and all the other

17 authors contributed substantially to the writing and revising of the manuscript. All authors have 18 read and approved the final version of the manuscript.

\section{Acknowledgements}

$20 \quad$ Not declared 
2 1. Ebrahimzadeh S. Determining The Standards Of Height And Weight In Iranian Children

3 Of 6-12 Years Of Aye And Comparing It With International Standards. 2002.

42 2. Mohammd K, Hosseini M, Noorbala A. Secular Trends In Growth (Weight And Height)

5 Of Children In Iran Over A Decade (1990-1 To 1999). Hakim Research Journal. 2006;9(1):1-8.

63 3aheri F, Fouad Am. Growth Normogram In 11-14 Year Old Female Students In Birjand

7 And Its Comparison With National Center For Health Statistic (Nchs) Standard. 2006.

8 4. The State Of The World's Children 1998: A Unicef Report. Malnutrition: Causes, 9 Consequences, And Solutions. Nutr Rev. 1998;56(4 Pt 1):115-23.

10 5. Hosseini M, Taslimi S, Dinarvand P, Jones M, Mohammad K. Trends In Weights, Heights, 11 Bmi And Comparison Of Their Differences In Urban And Rural Areas For Iranian Children And 12 Adolescents 2-18-Year-Old Between 1990-1991 And 1999. Child: Care, Health And 13 Development. 2010;36(6):858-67.

14 6. Razzaghy Azar M, Moghimi A, Montazer M, Sadeghi Hm, Golnari P, Sadigh N, Et Al. 15 Cross-Sectional Reference Values For Height, Weight And Body Mass Index Of Schoolchildren 16 Living In Tehran, Iran. Annals Of Human Biology. 2006;33(4):471-9.

17 7. Ayatollahi S. Age-Related Weight-For-Height Charts For South Iranian School Children. 18 Journal Of Tropical Pediatrics. 1995;41(3):181-5.

19 8. Mei Z, Yip R, Grummer-Strawn Lm, Trowbridge Fl. Development Of A Research Child 20 Growth Reference And Its Comparison With The Current International Growth Reference. 21 Archives Of Pediatrics \& Adolescent Medicine. 1998;152(5):471-9.

22 9. A Nb. Studying Height And Weight Of Male Students Aged 7-19 Years In Ardabil And 23 Comparing It With Nchs Standard And Similar Studies In Iran. . Journal Of Science And 24 Technology. 2005.

25 10. Langerodi M. Study Of Height And Weight Of Children Under Age 10 In Qazvin. Journal 26 Of Qazvin University Of Medical Sciences \& Health Services. 1998.

27 11. Frongillo E, Hanson K. Determinants Of Variability Among Nations In Child Growth. 28 Annals Of Human Biology. 1995;22(5):395-411.

29 12. Taghavi N.S Em Ka, Porheydari M. Studying The Height And Weight Of Children Aged 30 7-11 Years In Shahrood During Academic Years 2003-2004 And Comparing It With The Global 31 Standard. Journal Of Science Islamic Azad University. 2007;17(2):95-101.

32 13. Cole Tj. The Secular Trend In Human Physical Growth: A Biological View. Economics \& 33 Human Biology. 2003;1(2):161-8.

34 14. Ah Tb. Anthropometric Characteristics Of Students Aged 11-17 Years In Urmia And 35 Comparison With Nchs Standard. Research In Sport Sciences. 2005.

36 15. Aminorroaya A, Amini M, Mosavi Af, Sanaat Z. Increased Heights And Weights Of 37 Isfahani Female Children And Adolescents In Iran. Journal Of Tropical Pediatrics. 2002;48(6):377389.

39 16. Aminorroaya A, Amini M, Naghdi H, Zadeh Ah. Growth Charts Of Heights And Weights 40 Of Male Children And Adolescents Of Isfahan, Iran. Journal Of Health, Population And Nutrition. 41 2003:341-6.

42 17. Ershadi A. Statistical Indexes And Weight And Height Curves In 6-18 Years Old Students 43 Of Kashan In 2000. 2000. 
1 18. Ayatollahi S, Pour-Ahmad S, Shayan Z. Secular Trends In Growth Among School Children 2 Of Shiraz (Southern Iran) Born In The Post-War Period. Medical Journal Of The Islamic Republic 3 Of Iran (Mjiri). 2006;20(3):141-6.

4 19. Kuczmarski Rj. Cdc Growth Charts; United States. 2000.

5 20. Hauspie R, Vercauteren M, Susanne C. Secular Changes In Growth And Maturation: An 6 Update. Acta Paediatrica. 1997;86(S423):20-7.

7 21. Ahmadi A Va. A Survey Of Height And Weight Of Children And Adolescents Ii Kerman, 8 Iran, In 1997. Journal Of Kerman University Of Medical Sciences. 2014.

9 22. Sohrabi A, Karajibani M, Vahedi R. Comparison Of Mean Weight And Height Growth Of 10 Governmental And Private Students Of Primary Schools Of Zahedan District, Iran. 2006.

11 23. Akhi O Tm Kz, Kovsarian M. Studying The Height And Weight Of Female Students Aged 12 6-18years Old In Sari, Iran. Journal Of Mazandaran University Of Medical Sciences 2007.

13 24. Shidfar F Mm Am, Azizi H.R. Study Of Height, Weight And Body Mass Index Of Female 14 Students Aged 6-15 Years Old In Babol City In The Years 1374-81 And Their Comparison

15 With Reference To The United States Centers For Disease Control And Prevention (Cdc2000). 16 Iranian Journal Of Nutrition Sciences And Food Technology. 2007;2(3):13-22.

17 25. K H. Physical Growth Status Of Elementary School Students In Babol 1998. Journal Of 18 Babol University Of Medical Sciences.9-43.

19 26. Nemati A Na Dmh. Anthropometrics Factors Of Girls Of Ardabil Aged 7-19 Years And 20 Comparison Of Them With Nchs Standard. Journal Of Research Medical Sciences, Ardabil 21 University Of Medical Sciences. 2008;8(2):202-8.

22 27. Nemati A Nba. Anthropometrics Factors Of Girls Of Ardabil Aged 7-19 Years And 23 Comparison Of Them With Nchs Standard. Journal Of Ardabil University Of Medical Sciences. $24 \quad 2009 ; 8(2)$.

25 28. Baghianimoghadam B, Karbasi Sa, Golestan M, Kamran M. Determination Of Growth 26 Pattern Of 7-12 Years Old Children In Yazd City And Comparison Of It With Who Standards. J 27 Pak Med Assoc. 2012;62(12):1289-293.

28 29. Bayat P-D, Khazaei M, Ghorbani R, Ayubian M, Sohouli P, Ghanbari A. Growth Pattern 29 In 7-12 Years Old Arak Children (Central Iran) In Comparison With Other Ethnic Subgroups Of 30 Iran. Italian Journal Of Anatomy And Embryology. 2012;117(1):1-7.

31 30. Montazerifar F Km Sm. Study Of Growth Pattern In 19-19 Year-Old Girls In Zahedan 32 City. Journal Of Medical Sciences University Of Medical Sciences Shahid Sadoghi Of Yazd.

33 31. Habibi E, Hoseini M, Asaad Z. Match Between School Furniture Dimensions And 34 Children's Anthropometry In Isfahan Schools. Iran Occup Health. 2009;6(2):51-61.

35 32. Ebrahimzadeh S. Determining The Sandards Of Height And Weight For 6-12-Year-Old 36 Kids Of Mashad And Comparing It With International Standards. 2002.

37 33. Hafezi R, Mirmohammadi S, Mehrparvar A, Akbari H, Akbari H. An Analysis Of 38 Anthropometric Data On Iranian Primary School Children. Iranian Journal Of Public Health. 39 2010;39(4):78.

40 34. Tanner Jm. Growth As A Measure Of The Nutritional And Hygienic Status Of A 41 Population. Hormone Research In Paediatrics. 1992;38(Suppl. 1):106-15.

42 35. James Cole T. Assessment Of Growth2002. 383-98 P. 
1 36. Mozaffari Kh, Nabizade Al, Akbari M, Ahadi Z, Talaei B. Standardized Of Height, Weight 2 And Body Mass Index (Bmi) In Healthy 6-11-Year-Old Schoolgirls And Schoolboys, Yazd City 3 2010-2011. 2014.

4 37. Saffari F, Jalilolgadr S, Esmailzadehha N, Shariatinejad K. Anthropometric Indices In 6514 Year-Old Girls In Qazvin, Iran. Journal Of Isfahan Medical School. 2012;29(165).

6 38. Moher D, Liberati A, Tetzlaff J, Altman Dg. Preferred Reporting Items For Systematic 7 Reviews And Meta-Analyses: The Prisma Statement. Ann Intern Med. 2009;151(4):264-9, W64.

8 39. Fakharzadeh L, Javaherizadeh H, Sabeti F, Cheraghian B. Are Growth Curves For Iranian 9 School-Aged Children Different From The Nchs Standards? The Journal Of The Egyptian Public 10 Health Association. 2011;86(5 And 6):90-4.

11 40. Mirmohammadi S-J, Hafezi R, Mehrparvar Ah, Rezaeian B, Akbari H. Prevalence Of 12 Overweight And Obesity Among Iranian School Children In Different Ethnicities. Iranian Journal 13 Of Pediatrics. 2011;21(4):514.

14 41. Mirmohammadi $\mathrm{Sj}$, Hafezi R, Mehrparvar Ah, Gerdfaramarzi Rs, Mostaghaci M, 15 Nodoushan Rj, Et Al. An Epidemiologic Study On Anthropometric Dimensions Of 7-11-Year-Old 16 Iranian Children: Considering Ethnic Differences. Ergonomics. 2013;56(1):90-102.

17 42. Shahin M, Afzalpour Me, Fallah Z. Construction Of Height-Weight Growth Charts For 21818 Year Old Boys In Qayenat City In Iran: A Comparison With Nchs. Annals Of Biological 19 Research. 2012;3(5):2162-7.

20 43. Von Elm E, Altman Dg, Egger M, Pocock Sj, Gotzsche Pc, Vandenbroucke Jp. The 21 Strengthening The Reporting Of Observational Studies In Epidemiology (Strobe) Statement: 22 Guidelines For Reporting Observational Studies. Lancet. 2007;370(9596):1453-7.

23 44. Taghi Hs, Fatemeh E, Yaser S, Maryam M. The Prevalence Of Obesity And Its Relevant 24 Factors In High-School Students In Jahrom In 2014.

25 45. Fatemi Mj, Fararouei M, Moravej H, Dianatinasab M. Stunting And Its Associated Factors 26 Among 6-7-Year-Old Children In Southern Iran: A Nested Case-Control Study. Public Health 27 Nutrition. 2019;22(1):55-62.

28 46. Mehrparvar Ah, Hafezi R, Mirmohammadi Sj, Mostaghaci M, Davari Mh. Anthropometry 29 Of Iranian Guidance School Students With Different Ethnicities: A Comparative Study. Scientifica. $30 \quad 2015 ; 2015$.

31 47. Mehrparvar Ah, Mirmohammadi $\mathrm{Sj}$, Hafezi $\mathrm{R}$, Mostaghaci $\mathrm{M}$, Davari Mh. Static 32 Anthropometric Dimensions In A Population Of Iranian High School Students: Considering Ethnic 33 Differences. Human Factors. 2015;57(3):447-60.

34 48. Hosseini M, Kelishadi R, Yousefifard M, Qorbani M, Bazargani B, Heshmat R, Et Al. 35 Height-Adjusted Percentiles Evaluated Central Obesity In Children And Adolescents More 36 Effectively Than Just Waist Circumference. Acta Paediatrica. 2017;106(1):112-9.

37 49. Hosseini S, Afshari Safavi A, Esmaeil Zade A, Beig Rezaei S. Comparison Of 38 Anthropometric Indices Of The Children Aged 5-18 Years In Isfahan With Nchs Values. Iranian 39 Journal Of Epidemiology. 2017;13(2):119-27.

40 50. Lin-Su K, Vogiatzi Mg, New Mi. Body Mass Index And Age At Menarche In An 41 Adolescent Clinic Population. Clinical Pediatrics. 2002;41(7):501-7.

42 51. Bahrami N, Soleimani Ma, Chan Yh, Ghojazadeh M, Mirmiran P. Menarche Age In Iran: 43 A Meta-Analysis. Iranian Journal Of Nursing And Midwifery Research. 2014;19(5):444.

44 52. Chumlea Wc, Schubert Cm, Roche Af, Kulin He, Lee Pa, Himes Jh, Et Al. Age At 45 Menarche And Racial Comparisons In Us Girls. Pediatrics-Springfield-. 2003;111(1):110-3. 
1 53. Bratke H, Bruserud Is, Brannsether B, Aßmus J, Bjerknes R, Roelants M, Et Al. Timing 2 Of Menarche In Norwegian Girls: Associations With Body Mass Index, Waist Circumference And 3 Skinfold Thickness. Bmc Pediatrics. 2017;17(1):138.

4 54. Aryani I, Rachma Up, Rokhayati E, Moelyo Ag. Menstrual Cycle Patterns Of Indonesian 5 Adolescents. Paediatrica Indonesiana. 2018;58(3):101-5.

6 55. Jansen Ec, Herrán Of, Villamor E. Trends And Correlates Of Age At Menarche In 7 Colombia: Results From A Nationally Representative Survey. Economics \& Human Biology. $8 \quad 2015 ; 19: 138-44$.

9 56. Thomas F, Renaud F, Benefice E, De Meeus T, Guegan J-F. International Variability Of 10 Ages At Menarche And Menopause: Patterns And Main Determinants. Human Biology. 11 2001;73(2):271-90.

12 57. Ong Kk, Ahmed Ml, Dunger Db. Lessons From Large Population Studies On Timing And 13 Tempo Of Puberty (Secular Trends And Relation To Body Size): The European Trend. Molecular 14 And Cellular Endocrinology. 2006;254:8-12.

15 58. Villamor E, Marin C, Mora-Plazas M, Baylin A. Vitamin D Deficiency And Age At 16 Menarche: A Prospective Study. The American Journal Of Clinical Nutrition. 2011;94(4):1020-5.

17 59. Karapanou O, Papadimitriou A. Determinants Of Menarche. Reproductive Biology And 18 Endocrinology. 2010;8(1):115.

19 60. Ulijaszek S. Ethnic Differences In Patterns Of Human Growth In Stature. In: Reynaldo M, 20 Ferdinand H, Editors.: Nestec Ltd.; 2001. P. 1-20.

21 61. Fetuga M, Ogunlesi T, Adekanmbi A, Alabi A. Growth Pattern Of Schoolchildren In 22 Sagamu, Nigeria Using The Cdc Standards And 2007 Who Standards. Indian Pediatrics. 23 2011;48(7):523-8.

24 62. Cacciari E, Milani S, Balsamo A, Spada E, Bona G, Cavallo L, Et Al. Italian Cross25 Sectional Growth Charts For Height, Weight And Bmi (2 To 20 Yr). Journal Of Endocrinological 26 Investigation. 2006;29(7):581-93.

27 63. El-Mouzan Mi, Al-Herbish As, Al-Salloum Aa, Qurachi Mm, Al-Omar Aa. Growth Charts 28 For Saudi Children And Adolescents. Saudi Medical Journal. 2007;28(10):1555-68.

29 64. Neyzi O, Furman A, Bundak R, Gunoz H, Darendeliler F, Bas F. Growth References For 30 Turkish Children Aged 6 To 18 Years. Acta Paediatrica. 2006;95(12):1635-41.

31 65. Nwokoro So, Ifada K, Onochie O, Olomu J. Anthropometric Assessment Of Nutritional 32 Status And Growth Of 10 Individuals In Benin City (Nigeria) Metropolis. Pakistan Journal Of 33 Nutrition. 2006;5(2):117-21.

34 66. Bener A, Kamal Aa. Growth Patterns Of Qatari School Children And Adolescents Aged 63518 Years. Journal Of Health, Population And Nutrition. 2005:250-8.

36 67. Fuiano N, Tucci A, Pietrobelli A. Growth Curves In Pediatrics. Pilot Study In A City Of 37 South Of Italy. Minerva Pediatrica. 2005;57(5):297-303.

38 68. Delemarre-Van De Waal Ha. Environmental Factors Influencing Growth And Pubertal 39 Development. Environmental Health Perspectives. 1993;101(Suppl 2):39-44.

40 69. Saha C, Eckert Gj, Pratt Jh, Shankar Rr. Onset Of Overweight During Childhood And 41 Adolescence In Relation To Race And Sex. The Journal Of Clinical Endocrinology \& Metabolism. $42 \quad 2005 ; 90(5): 2648-52$.

43 70. Droomers M, Gross R, Schultink W, Sastroamidjojo S. High Socioeconomic Class 44 Preschool Children From Jakarta, Indonesia Are Taller And Heavier Than Nchs Reference 45 Population. European Journal Of Clinical Nutrition (United Kingdom). 1995. 
1 71. Tanner Jm. 1 Normal Growth And Techniques Of Growth Assessment. Clinics In 2 Endocrinology And Metabolism. 1986;15(3):411-51.

3 72. Anderson M, Dewey K, Frongillo E, Garza C, Haschke F, Kramer M, Et Al. An Evaluation 4 Of Infant Growth-The Use And Interpretation Of Anthropometry In Infants. Bulletin Of The World 5 Health Organization. 1995;73(2):165-74.

6 73. Choobineh A, Rahimi Fard H, Jahangiri M, Mahmood Khani S. Musculoskeletal Injuries 7 And Their Associated Risk Factors. Iran Occupational Health. 2012;8(4):70-81.

8

9 
1 Table 1: Profile of the studies included in the quantitative meta-analysis.

\begin{tabular}{|c|c|c|c|c|c|c|}
\hline \multirow[t]{2}{*}{ ROW } & \multirow[t]{2}{*}{ Study } & \multirow[t]{2}{*}{ Year } & \multirow[t]{2}{*}{ Area } & \multicolumn{3}{|c|}{$\mathbf{N}$} \\
\hline & & & & Male & Female & Total \\
\hline 1 & Mohammad K. (2) & 1991 & Iran & 7872 & 7896 & 15768 \\
\hline 2 & Hosseini M.(5) & 1991 & $\begin{array}{c}\text { Iran } \\
\text { (Rural, Urban) }\end{array}$ & 11175 & 11174 & 22349 \\
\hline 3 & Ayaatollahi S M T A.(7) & 1989 & Shiraz & 642 & 565 & 1207 \\
\hline 4 & Motie Langarodi H. (10) & 1992 & Ghazvin & 1103 & 1113 & 2236 \\
\hline 5 & Aminorroaya M. $(15,16)$ & 1997 & Esfahan & 4150 & 4386 & 8536 \\
\hline 6 & Ershadi A.(17) & 1998 & Kashan & - & 8093 & 8093 \\
\hline 7 & Ahmadi A. (21) & 1998 & Kerman & 3287 & 3419 & 6706 \\
\hline 8 & Mohammad K. (2) & 1999 & Iran & 8904 & 8880 & 17784 \\
\hline 9 & Hosseini M. (5) & 1999 & $\begin{array}{c}\text { Iran } \\
\text { ( Rural,Urban) }\end{array}$ & 12598 & 12598 & 25196 \\
\hline 10 & Hajian K.(25) & 2000 & Babol & 498 & 500 & 994 \\
\hline 11 & Montazerifar F.(30) & 2000 & Zahedan & - & 1404 & 1404 \\
\hline 12 & Ebrahimzadeh S. (32) & 2000 & Mashahd & 334 & 338 & 672 \\
\hline
\end{tabular}

2 
Table 1: Continued ...

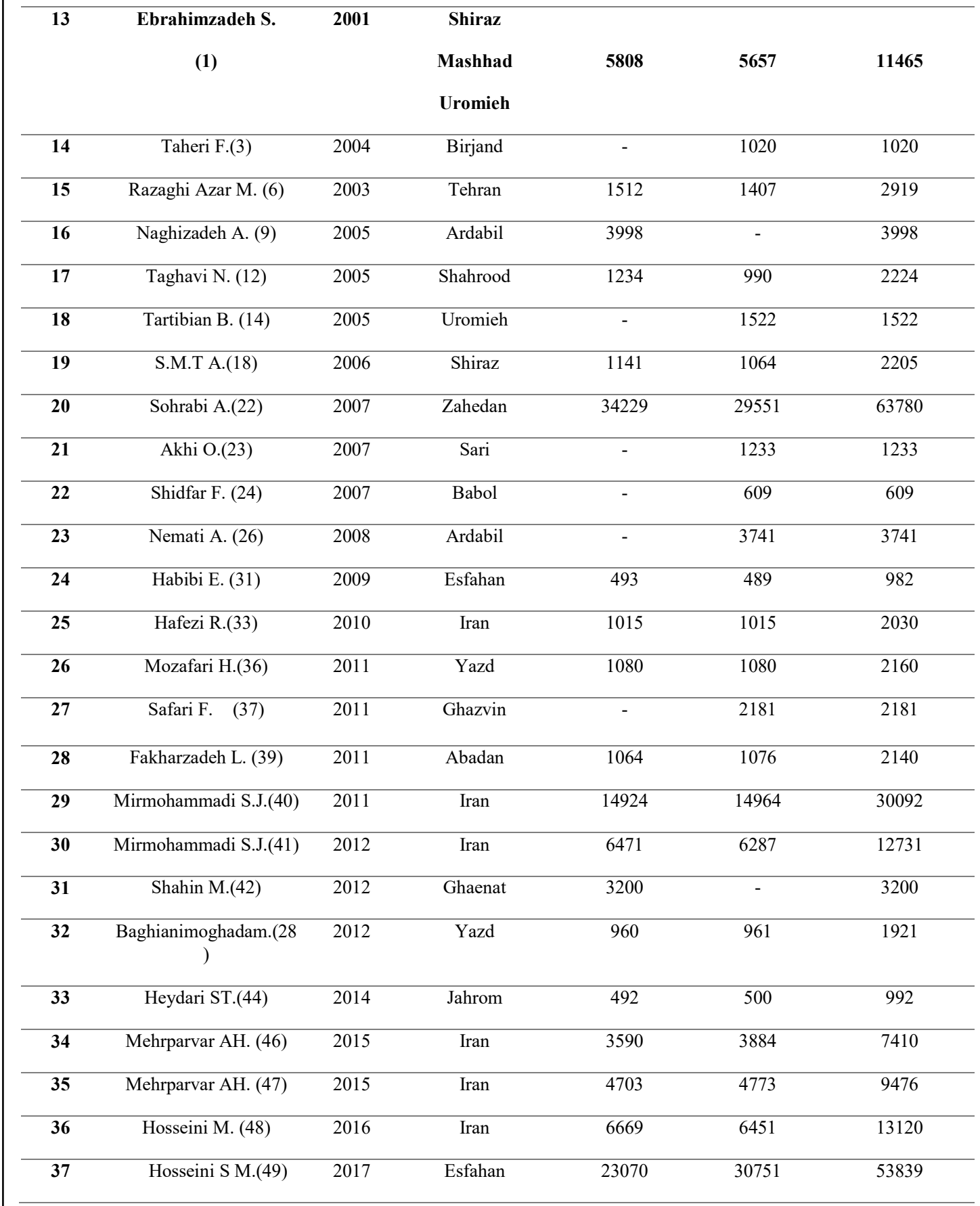

1

2 
1 Table 2: Comparison of the mean height of Iranian girls and boys aged 7 to 18 years with the global standards

Height length (cm)

Children and adolescents 7 to

Age

Gender 12 years old in Iran

(Year)
Weight

*Mean

(cm)

\section{$\overline{\boldsymbol{X}}$}

Height length (cm)

\begin{tabular}{|c|c|c|c|c|c|c|c|c|}
\hline & & \multirow[b]{2}{*}{$\bar{X}$} & \multicolumn{2}{|c|}{$\% 95 \mathrm{CI}$} & \multirow[b]{2}{*}{$\bar{X}$} & \multirow[b]{2}{*}{ WHO } & \multirow[b]{2}{*}{$\mathrm{CDC}$} & \multirow[b]{2}{*}{ NCHS } \\
\hline & & & Lower & Upper & & & & \\
\hline & Male & 119.30 & 117.33 & 121.27 & 119.36 & 121.73 & 122.03 & 121.76 \\
\hline 7 & Female & 118.86 & 115.92 & 121.80 & 118.54 & 120.81 & 121.76 & 121.49 \\
\hline \multirow{2}{*}{8} & Male & 124.63 & 122.71 & 126.55 & 124.96 & 127.26 & 128.12 & 127.87 \\
\hline & Female & 124.24 & 121.50 & 126.99 & 123.80 & 126.55 & 127.82 & 127.58 \\
\hline \multirow{3}{*}{9} & Male & 130.90 & 127.08 & 132.10 & 130.11 & 132.56 & 133.73 & 133.51 \\
\hline & Female & 129.84 & 127.11 & 132.57 & 129.36 & 132.49 & 133.13 & 132.92 \\
\hline & Male & 135.05 & 133.21 & 136.90 & 135.40 & 137.77 & 138.82 & 138.61 \\
\hline \multirow[t]{2}{*}{10} & Female & 135.59 & 132.93 & 138.25 & 134.91 & 138.63 & 138.21 & 137.98 \\
\hline & Male & 139.96 & 138.01 & 141.90 & 139.54 & 143.11 & 143.73 & 143.52 \\
\hline \multirow[t]{2}{*}{11} & Female & 141.72 & 138.99 & 144.45 & 140.98 & 144.99 & 144.26 & 143.97 \\
\hline & Male & 144.73 & 142.24 & 147.22 & 143.75 & 149.08 & 149.30 & 149.04 \\
\hline 12 & Female & 147.23 & 143.95 & 150.50 & 146.40 & 151.23 & 151.48 & 151.19 \\
\hline \multirow[t]{2}{*}{13} & Male & 150.64 & 147.52 & 153.75 & 149.02 & 156.04 & 156.40 & 156.08 \\
\hline & Female & 151.74 & 148.57 & 154.92 & 151.31 & 156.37 & 157.34 & 157.15 \\
\hline \multirow[t]{2}{*}{14} & Male & 157.29 & 153.87 & 160.70 & 155.84 & 163.18 & 164.14 & 163.84 \\
\hline & Female & 154.93 & 152.39 & 157.47 & 154.68 & 159.78 & 160.47 & 160.39 \\
\hline \multirow[t]{2}{*}{15} & Male & 163.53 & 160.21 & 166.85 & 162.50 & 168.95 & 170.13 & 169.94 \\
\hline & Female & 156.45 & 154.39 & 158.52 & 156.21 & 161.66 & 161.89 & 161.85 \\
\hline \multirow[t]{2}{*}{16} & Male & 167.87 & 165.18 & 170.55 & 167.56 & 172.89 & 173.61 & 173.50 \\
\hline & Female & 157.40 & 155.83 & 158.97 & 157.05 & 162.51 & 162.50 & 162.54 \\
\hline
\end{tabular}




\begin{tabular}{lllllllll}
\hline 17 & Male & 170.68 & 168.54 & 172.82 & 170.06 & 175.16 & 175.34 & 175.29 \\
& & & & & & & & \\
\cline { 3 - 8 } & Female & 157.87 & 156.75 & 158.98 & 157.41 & 162.85 & 162.92 & 162.91 \\
\hline 18 & Male & 171.09 & 169.72 & 172.47 & 171.12 & 176.14 & 176.18 & 176.16 \\
& Female & 157.75 & 156.79 & 158.71 & 157.59 & 163.05 & 163.13 & 163.12 \\
& & & & & & & & \\
\end{tabular}

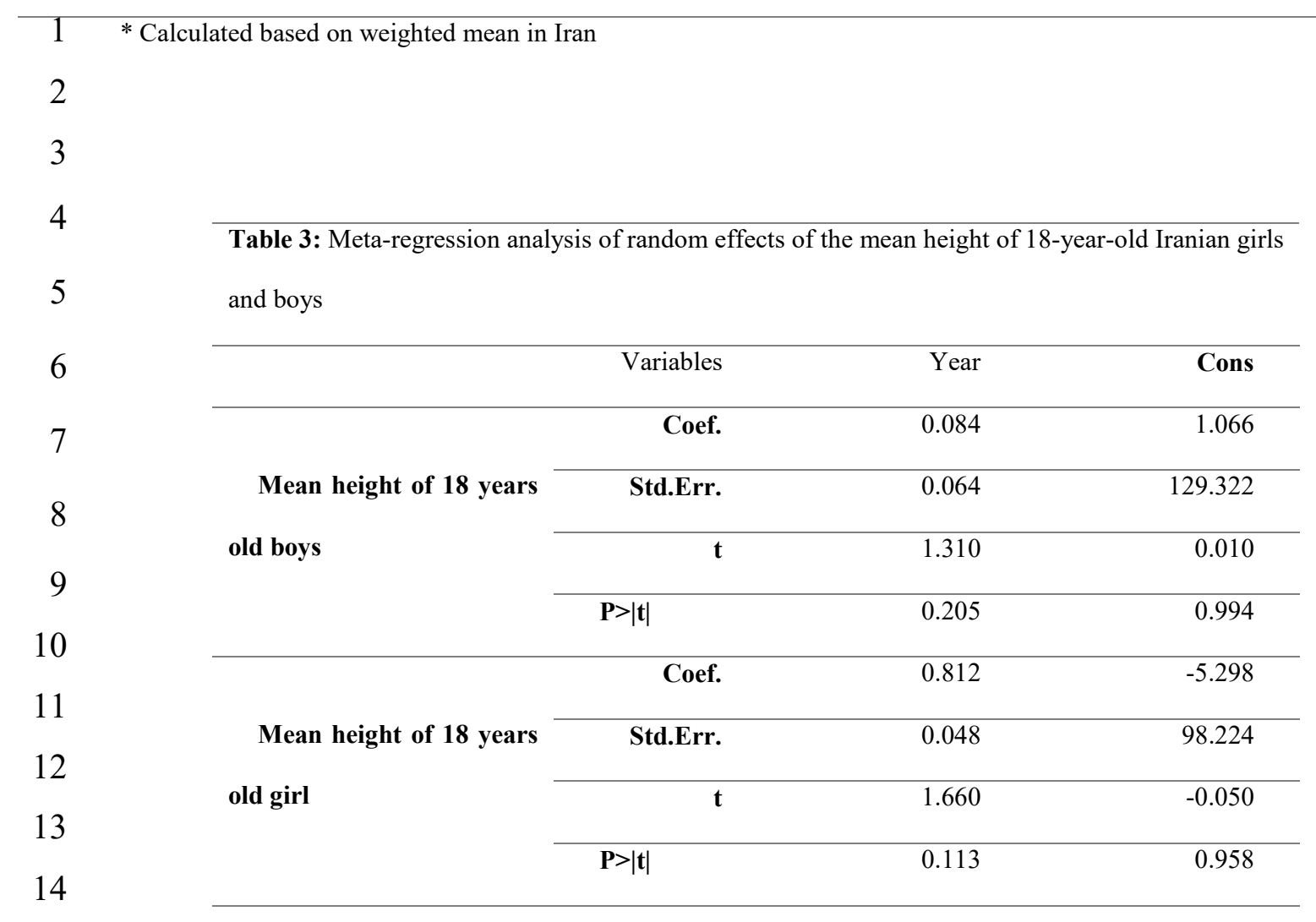

15

16 Table 4: Comparison of the mean height of 18-year-old Iranian girls and boys based on ethnicity

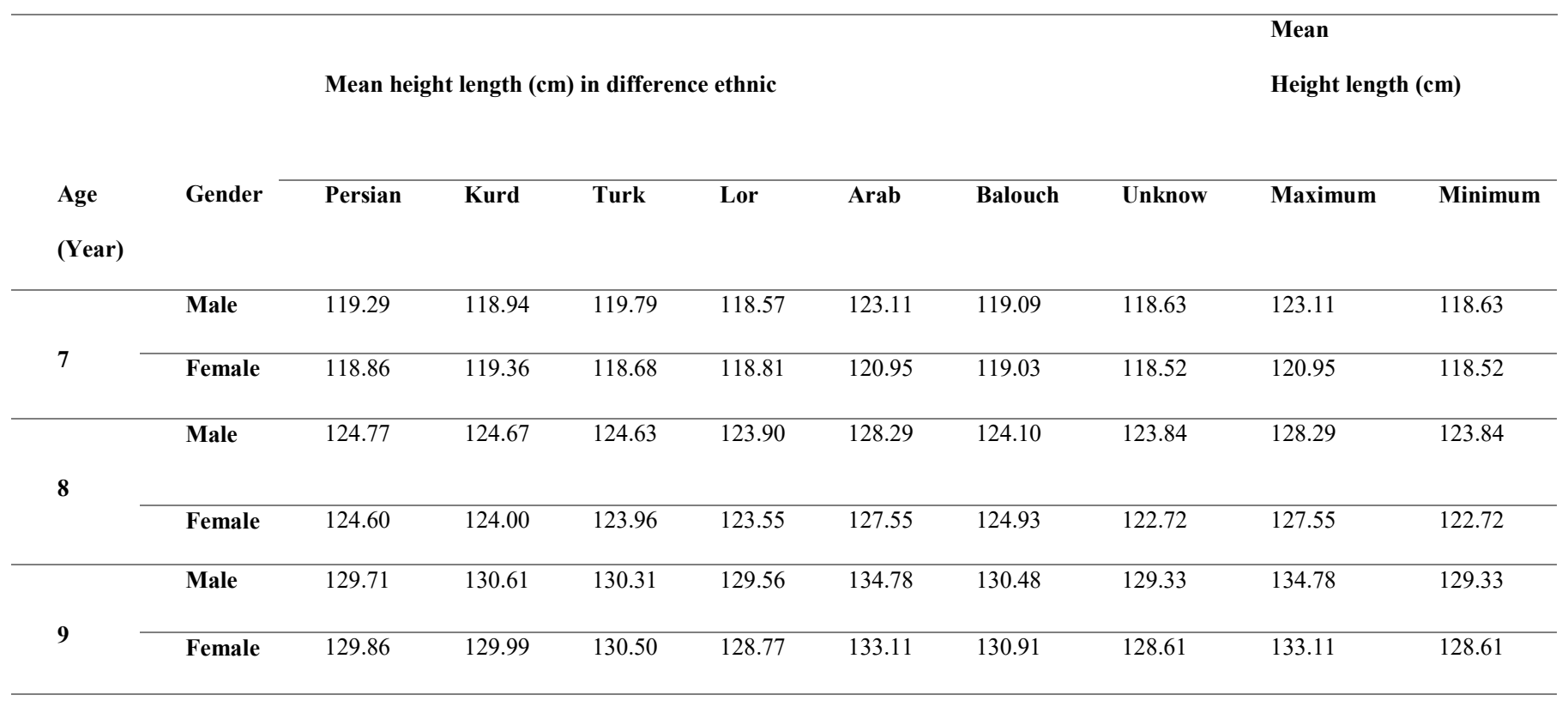




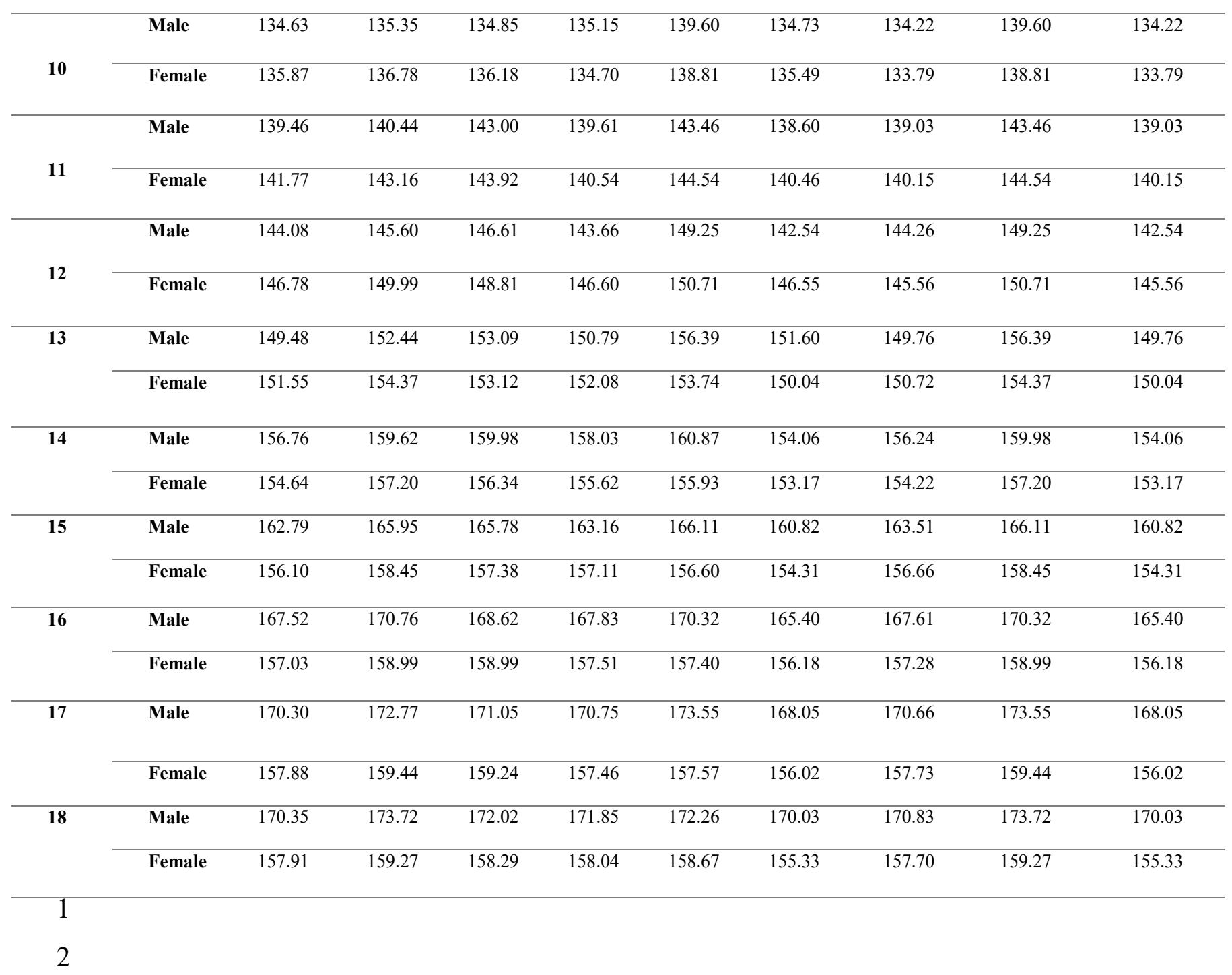


Figures

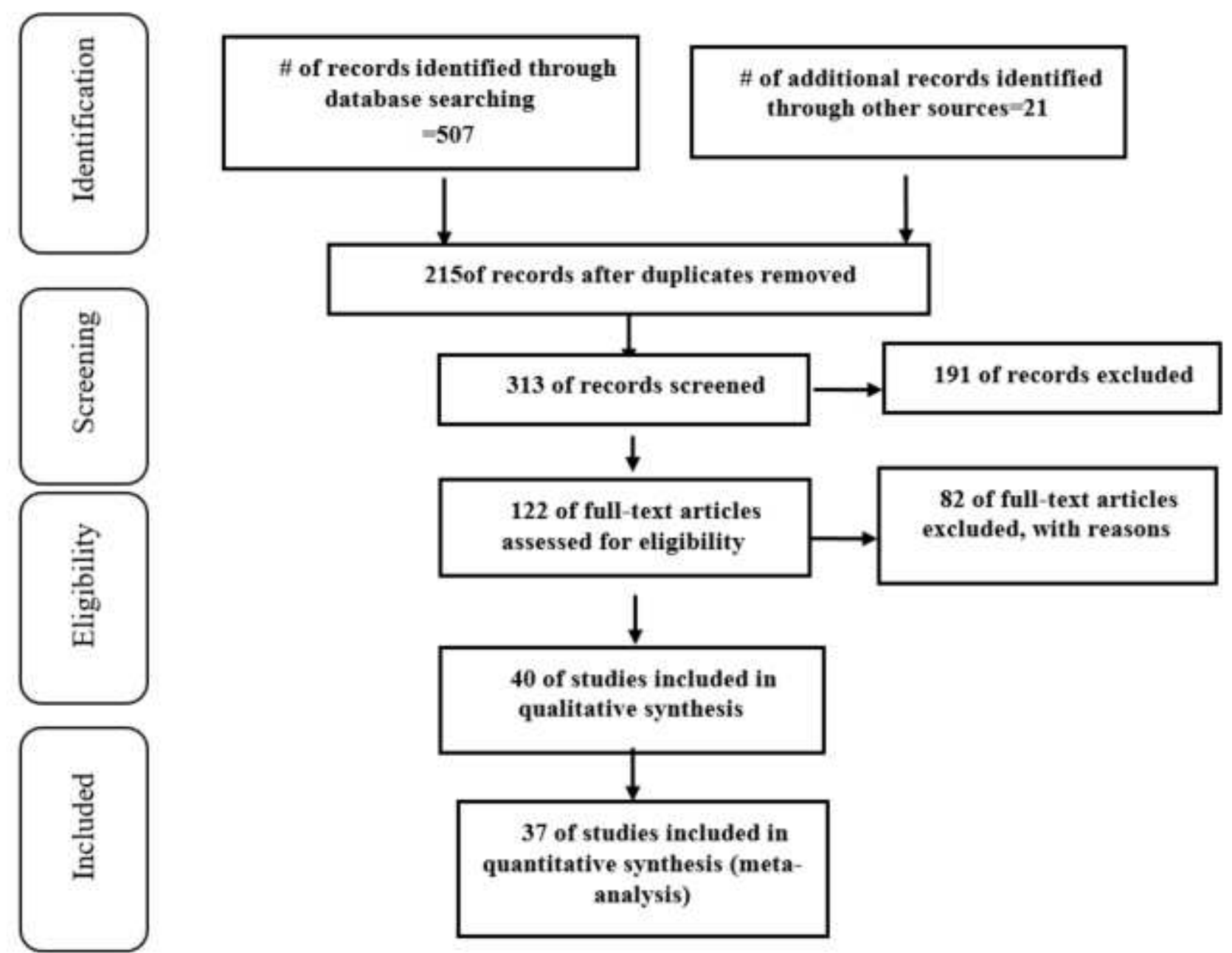

Figure 1

Diagram of meta-analysis in accordance with PRISMA 


\begin{tabular}{|c|c|c|c|}
\hline Heydari ST. (2014) & 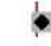 & $159.60(159.10,160.10)$ & 4.72 \\
\hline Mehrparvar AH. (2015) & $\bullet$ & $158.67(158.29,159.05)$ & 4.74 \\
\hline Mehrparvar AH. (2015) & 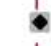 & $159.09(158.72,159.46)$ & 4.75 \\
\hline Mehrparvar AH. (2015) & $\bullet$ & $158.44(158.08,158.80)$ & 4.75 \\
\hline Mehrparvar AH. (2015) & - & $160.19(159.78,160.60)$ & 4.74 \\
\hline Mehrparvar AH. (2015) & $\bullet$ & $159.27(158.86,159.68)$ & 4.74 \\
\hline Mehrparvar AH. (2015) & $\bullet$ & $155.15(154.81,155.49)$ & 4.75 \\
\hline Akhi O. (2007) & $\geqslant$ & $161.00(160.73,161.27)$ & 4.76 \\
\hline MontazeriFar F. (2000) & $\bullet$ & $155.50(155.19,155.81)$ & 4.76 \\
\hline Nemati A. (2008) & 4 & $158.20(157.94,158.46)$ & 4.76 \\
\hline Aminorroaya A. (1997) & $\bullet$ & $159.00(158.82,159.18)$ & 4.77 \\
\hline Hosseini M. (2016) & 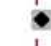 & $159.60(159.44,159.76)$ & 4.77 \\
\hline Mohamad K. (1991) & $\bullet$ & $155.00(154.87,155.13)$ & 4.78 \\
\hline Arshadi A. (1998) & $\bullet$ & $158.40(158.27,158.53)$ & 4.78 \\
\hline Mohamad K. (1999) & $\bullet$ & $158.00(157.88,158.12)$ & 4.78 \\
\hline Hoseini M. (1991) & $\dot{\phi}$ & $157.00(156.89,157.11)$ & 4.78 \\
\hline Hoseini M. (1991) & $\otimes_{1}^{\prime}$ & $153.00(152.89,153.11)$ & 4.78 \\
\hline Hoseini M. (1999) & 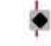 & $159.00(158.90,159.10)$ & 4.78 \\
\hline Hoseini M. (2008) & - & $157.00(156.90,157.10)$ & 4.78 \\
\hline Mirmohammadi SJ. (2011) & - & $158.00(157.92,158.08)$ & 4.78 \\
\hline Hosseini S M. (2017) & $\bullet$ & $153.80(153.72,153.88)$ & 4.78 \\
\hline Overall $(\mathrm{l}$-squared $=99.9 \%, p=0.000)$ & 1 & $157.75(156.79,158.72)$ & 100.00 \\
\hline NOTE: Weights are from random effects analysis & i & & \\
\hline $\begin{array}{c} \\
-161 \\
\end{array}$ & $\begin{array}{r}16 \\
16\end{array}$ & & \\
\hline
\end{tabular}

\section{Figure 2}

Estimation of the mean height of 18-year-old Iranian girls and boys based on the date of the study 

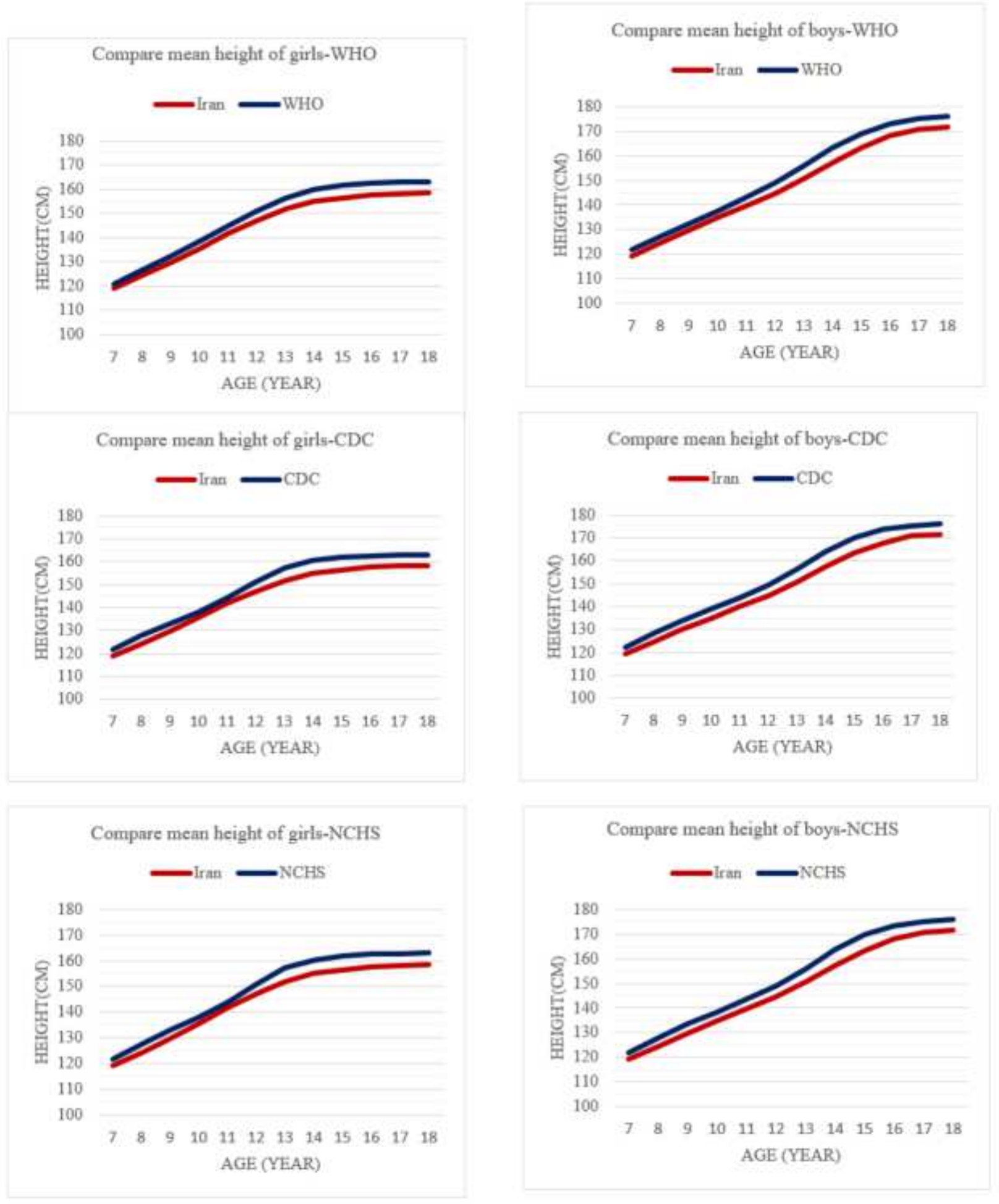

\section{Figure 3}

Comparison of the mean height of Iranian girls and boys during growth with the global standards 

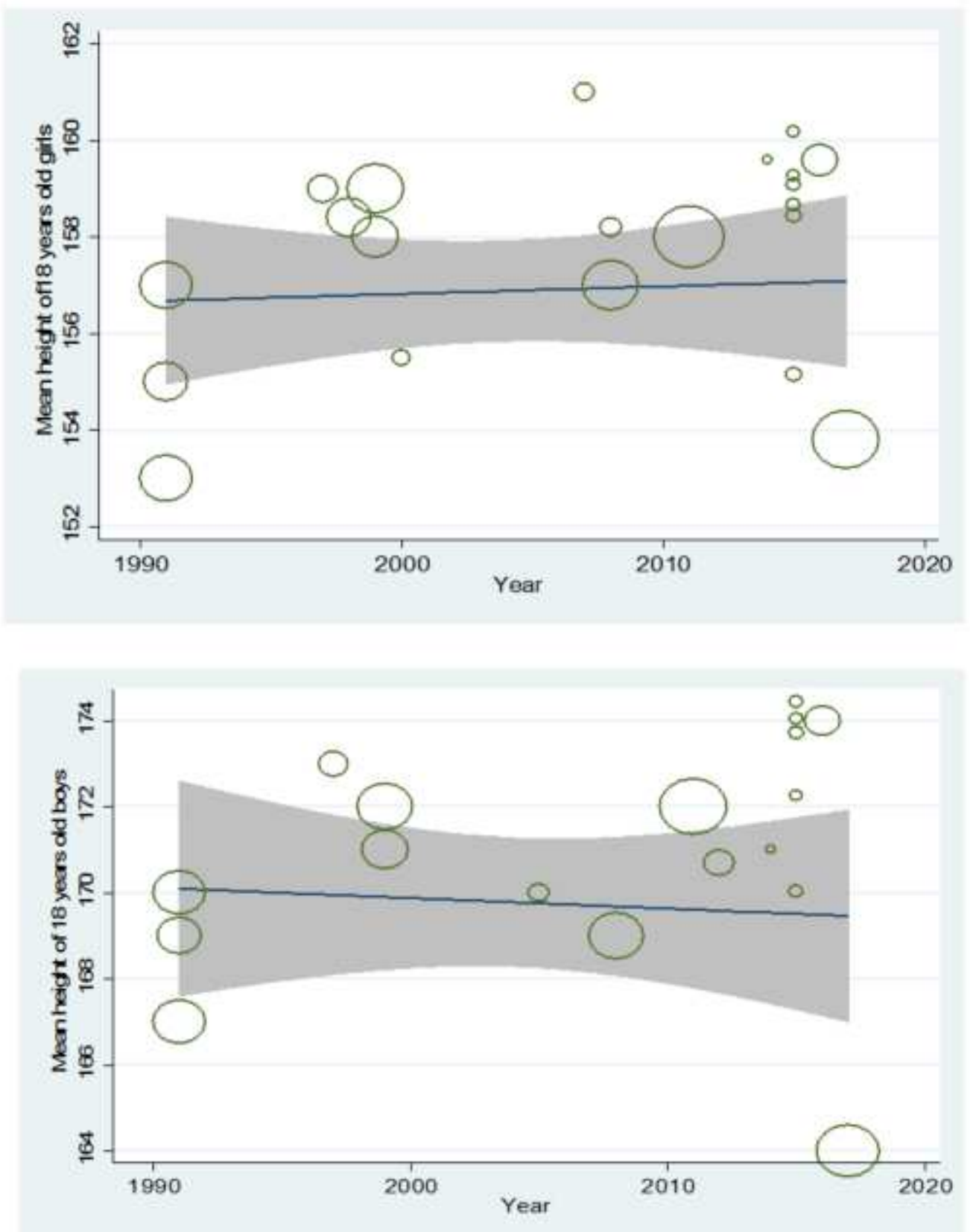

\section{Figure 4}

Random effects model of the mean height of 18-year-old Iranian girls and boys * Larger circles represent larger sample sizes. * Width of the diagram represents the distance.

\section{Supplementary Files}

This is a list of supplementary files associated with this preprint. Click to download.

- BPEDD2000015R1PRISMA2009checklist.doc 